\title{
EXPROPRIAÇÕES, SOFRIMENTOS, LUTAS E ESPERANCุAS: BREVES REFLEXÕES SOBRE A QUESTÃO AGRÁRIA BRASILEIRA ${ }^{1}$
}

\author{
Diego Salomão Candido de O. Salvador \\ Graduando do Curso Superior de Licenciatura em Geografia no CEFETRN \\ diegolisse@yahoo.com.br \\ José Aldivan de A. Silva \\ Graduando do Curso Superior de Licenciatura em Geografia no CEFETRN \\ tioaldi@yahoo.com.br
}

\begin{abstract}
RESUMO
Este trabalho tem como principal objetivo refletir sobre a questão agrária no Brasil. Para isso, atenta-se para o histórico de expropriações e sofrimentos que marcam a vida dos trabalhadores do campo no país, bem como para as lutas e esperanças destes, que anseiam pelo direito a um pedaço de terra e, assim, poder ter uma vida mais digna, caracterizada por tranqüilidade e qualidade. As discussões colocadas no trabalho são decorrentes de algumas pesquisas bibliográficas, em livros, periódicos e sites da internet, sobre o assunto. Além disso, colocam-se em tela versos de poesia popular que retratam a questão, como também ilustrações da vida dos trabalhadores sem-terra em acampamentos localizados em margens de estradas no Estado do Rio Grande do Norte, à espera de um pedaço de chão que encontra-se atualmente improdutivo, para produzir a sua subsistência. A postura metodológica adotada nas reflexões do trabalho é a crítica.
\end{abstract}

PALAVRAS-CHAVE: Questão agrária brasileira. Expropriações. Lutas. Reforma agrária. Esperanças.

\section{EXPROPIACIONES, SUFRIMIENTOS, LUCHAS Y ESPERANZAS: BREVES REFLEXIONES SOBRE LA CUESTIÓN AGRARIA BRASILEÑA}

\section{RESUMEN}

Este trabajo tiene como el objetivo principal cavilar sobre la cuestión agraria en lo Brasil. Para iso, atentase para el histórico de expropiaciones y sufrimientos que marca la vida de los trabajadores del campo en el país, además para las luchas y esperanzas de eses, que anhelan por lo derecho a un trozo de tierra y, así, poder tener una vida más digna, caracterizado por tranquilidad y cualidad. Las discusiones colocadas en el trabajo son originadas de algunas pesquisas bibliográficas, en libros, periódico y sitios del Internet, sobre el asunto. Además, se ponen en pantalla versos de la poesía popular que retratan la cuestión, como también ilustraciones de la vida de los trabajadores sin-tierra en acampamientos localizados en bordes de la carretera en lo Estado del "Rio Grande do Norte", en la espera de un trozo de tierra, que encuentrase actualmente improductivo, para producir la sua subsistencia. La postura metodológica adoptada en las reflexiones del trabajo es la crítica.

PALABRAS-CLAVE: Cuestión agraria brasileña. Expropiaciones. Luchas. Reforma agraria. Esperanzas.

\footnotetext{
${ }^{1}$ Este trabalho é decorrente de discussões efetuadas durante a disciplina Geografia Agrária, ministrada pela Professora Ms. Nubélia Moreira, no Curso Superior de Licenciatura em Geografia do CEFET-RN, ano de 2006.
} 


\section{EXPROPRIAÇÕES, SOFRIMENTOS, LUTAS E ESPERANCุAS: BREVES REFLEXÕES SOBRE A QUESTÃO AGRÁRIA BRASILEIRA}

\section{PALAVRAS INICIAIS}

Este trabalho tem como principal objetivo refletir sobre a questão agrária no Brasil, atentando para o histórico de expropriações e sofrimentos que marcam a vida dos trabalhadores do campo no país, bem como para as lutas e esperanças destes, que anseiam um dia terem direito a um pedaço de terra e, assim, poder ter uma vida mais digna, caracterizada por tranqüilidade e qualidade. As discussões presentes no trabalho, acerca da questão agrária brasileira, são decorrentes de algumas pesquisas bibliográficas, em livros, periódicos e sites da internet, sobre o assunto.

Iniciando essas discussões, vale esclarecer a que se refere a questão agrária? Esta liga-se às transformações que se dão nas relações de produção, fundamentando-se no como se produz e no de que forma se produz. Já a questão agrícola refere-se a outras bases de consideração, baseando-se em aspectos estritamente relacionados a produção em si mesma, tendo como alicerce o onde se produz, o que se produz e o quanto se produz (SILVA, 1993). Sendo assim, diz-se que enquanto na questão agrícola preocupa-se tão somente com a produção e o lucro decorrente desta, na agrária há também a atenção para quem participa do processo produtivo, no caso os trabalhadores.

É importante destacar que as questões agrária e agrícola caminham de mãos dadas. Seria irresponsabilidade considerá-las de maneira compartimentalizada e estanque. Todavia, também é preciso dizer que "[...] muitas vezes a maneira pela qual se resolve a questão agrícola pode servir para agravar a questão agrária” (SILVA, 1993, p. 11).

$\mathrm{Na}$ atualidade, observa-se uma intensificação nas discussões sobre a questão agrária brasileira. Essa questão encontra-se nos cenários político e popular, sendo alvo de discursos e protestos em âmbito nacional. Isso ocorre não apenas por que nos dias atuais se tem mais liberdade para refletir e debater sobre essa questão, mas também porque ela vem cada vez mais se agravando, em função da forte capitalização das relações no campo.

Outro ponto também bastante perceptível no momento atual é a crescente entrada das novas tecnologias no processo produtivo agrícola, o que já ocorre desde meados do século XX. O problema é que essa entrada tecnológica tem como principal escopo o aumento da produtividade para atender as premissas capitalistas do mercado, e não as necessidades sociais tão urgentes no Brasil. Com isso, a modernização do campo sempre é acompanhada pela incorporação de novas terras aos grandes latifúndios, tornando-os ainda maiores e intensificando o problema agrário. É por isso que Araújo (2007) quando se refere a essa modernização diz que ela incrementa as bases técnicas e agrava a questão fundiária. É necessário propor tecnologias alternativas às que estão em voga, tendo também como referência o consumo dos trabalhadores e não apenas o da burguesia, o que significa desencadear uma produção em grande escala, uma produção para o todo social e não para o individual. Em um sistema de produção socialista, isto é, dedicado a atender as necessidades de todos, o trabalhador é o proprietário dos frutos decorrentes do seu trabalho, que aumentam de acordo com a elevação da produtividade. 
Após essas considerações iniciais, o trabalho apresenta-se com a seguinte segmentação: primeiro, discuti-se o histórico de expropriações e sofrimentos que marcam os trabalhadores do campo no Brasil; depois, colocam-se em destaque breves reflexões sobre as lutas desses trabalhadores pelo direito a terra para produzir; e por último, reflete-se um pouco acerca de uma estratégia que traz esperanças para todos os trabalhadores rurais: a reforma agrária.

\section{QUESTÃO AGRÁRIA NO BRASIL: UM HISTÓRICO DE EXPROPRIAÇÕES E SOFRIMENTOS}

"[...] é possível reduzir a dívida social com os milhões de indigentes e pobres que vivem no campo, injetando ao mesmo tempo um novo dinamismo na economia nacional e descartando as práticas de exploração predatória dos imensos recursos naturais do país" (SACHS, 2002, p. 91).

Até o início da colonização do Brasil, que aconteceu em meados do século XVI, a terra era utilizada, pelos que aqui viviam, de maneira coletiva, sendo considerada um bem da natureza para o uso e a subsistência de todos os que se dispusessem a trabalhá-la.

Com o advento da colonização adotaram-se modelos de divisão da terra - capitanias hereditárias e sesmarias - em que doavam-se grandes lotes a particulares. Esses particulares, segundo Bauer (1998), eram homens de posses, que dispunham de condições para adquirir escravos e gados. Mas por que grandes lotes de terras? Primeiro, para atrair portugueses de posses e de bem para receber lotes na nova terra. Segundo, para dar possibilidades de serem desenvolvidos grandes cultivos para atender as premissas externas da metrópole. Dessa maneira, pode-se dizer que a gênese do grande latifúndio no Brasil remete para os idos coloniais.

Em 1850, acontecem dois fatos importantes: a proibição do tráfico negreiro e a criação da Lei de Terras. A proibição do tráfico negreiro ligava-se a interesses ingleses, já que a Inglaterra caminhava a largos passos para o desenvolvimento industrial, necessitando, com isso, da disponibilidade de uma massa de trabalhadores assalariados e, conseqüentemente, da constituição de um mercado consumidor. Já a Lei de Terras explicitava que todas as terras no país só poderiam ser adquiridas mediante compra e venda. Diante dessa compra e venda, a lei previa que o governo destinaria os rendimentos obtidos ao financiamento da vinda de colonos da Europa, que substituiriam os escravos. Para Silva (1993, p. 27-28) com a aplicação dessa lei

matavam-se [...] dois coelhos com uma só cajadada. De um lado, restringiase $\mathrm{o}$ acesso às terras (devolutas ou não) apenas àqueles que tivessem dinheiro para comprá-las. De outro, criavam-se as bases para a organização de um mercado de trabalho livre para substituir o sistema escravista.

A partir de 1888, começa a ocorrer no Brasil um tímido desenvolvimento industrial, o qual, inicialmente, era marcado pelo atendimento das necessidades do mercado interno. $\mathrm{Na}$ década de 1930, em decorrência da crise de 29, provocada pela quebra da Bolsa de Nova 
York, e do colapso do setor cafeeiro, o setor industrial vai consolidando-se paulatinamente no país. No início dos anos de 1960, ocorrem acontecimentos bastante importantes para o desenrolar da questão agrária brasileira. É quando instalam-se no país fábricas de máquinas e insumos agrícolas. São implantadas indústrias de tratores e equipamentos agrícolas (arados, grades, dentre outros), fertilizantes químicos, rações, medicamentos veterinários, dentre outros elementos. Em suma, começa a ocorrer a modernização do campo, ou, como preferem alguns, a revolução verde.

Essa modernização não foi realizada sobre alicerces sociais, mas meramente econômicos. Não houve e continua não existindo preocupações agrárias, mas somente agrícolas. A estrutura agrária brasileira, marcada pelo grande latifúndio, foi reforçada. As palavras de Bauer (1998, p. 06) explicitam o que representou essa modernização conservadora do campo brasileiro:

num curtíssimo espaço de tempo, o Brasil transformou-se de uma sociedade eminentemente rural, em urbana, de uma economia agrária em industrial. Essa extraordinária transformação da sociedade brasileira, não reduziria, contudo, o poder ou a importância da grande propriedade rural. Ao contrário, o processo em andamento, definido como modernização conservadora, iria contribuir para modernizar, aumentar ou criar novos latifúndios [...].

Vale destacar que não se opõe aqui ao processo de modernização empreendido não só no Brasil, mas em escala mundial. O que se critica é como esse processo se dá, tendo como pilar fundamental a expropriação dos trabalhadores e o favorecimento do grande capital ${ }^{2}$. Acredita-se que seria melhor para todos a adoção de um processo de modernização em que o pilar fundamental fosse o bem-estar coletivo. Entretanto, esse pilar favorecedor da coletividade sempre esbarra em objetivos políticos obscuros, que geralmente estão por trás das propostas colocadas em tela no Brasil.

Em decorrência dessa modernização conservadora ocorreu, a partir dos anos de 1970, o fechamento da fronteira agrícola no país. Essa fronteira era marcada pela pequena produção, sendo o destino das famílias camponesas expropriadas pelo grande capital. Quando essa fronteira é fechada, passando a ser marcada premeditadamente por terras-sem-dono, passa a intensificar-se o deslocamento desorganizado de grandes contingentes populacionais para as periferias urbanas. Dessa forma, os problemas do campo são levados para as cidades, onde, muitas vezes, se agravam. O homem trabalhador passa de expropriado rural a expropriado urbano.

Os versos de Patativa do Assaré (1986, p. 89-92), em A Triste Partida, ilustram o que acontece com o homem do campo quando é obrigado a sair de seu lugar, no momento em que a expropriação torna-se explícita, para buscar melhores condições de vida no espaço urbano:

\footnotetext{
${ }^{2}$ Santos (2003) diz que esse processo de modernização gera a globalização perversa que abala as estruturas sociais no mundo inteiro. Para esse pensador, a perversidade na globalização só será extinta quando medidas forem tomadas de baixo para cima, ou seja, tendo os desfavorecidos como atores ativos e conscientes.
} 
Nós vamo a São Palo, que a coisa ta feia;

Por terras aléia

Nós vamo vagá.

Se o nosso destino não fô tão mesquinho,

Pro mêrmo cantinho nós torna a vortá.

$[\ldots]$

Chegaro em São Palo - sem cobre, quebrado.

O pobre, acanhado,

Percura um patrão.

Só vê cara estranha, da mais feia gente,

Tudo é diferente

Do caro torrão.

Trabaia dois ano, três ano e mais ano,

E sempre no prano

De um dia inda vim.

Mas nunca ele pode, só veve devendo,

E assim vai sofrendo

Tormento sem fim.

$[\ldots]$

Do mundo afastado, sofrendo desprezo,

Ali vê preso

Devendo ao patrão.

O tempo rolando, vai dia, vem dia,

E aquela famia

Não vorta mais não!

Distante da terra tão seca mas boa,

Exposto à garoa,

À lama e ao pau,

Faz pena o nortista, tão forte, tão bravo,

Vivê como escravo

Nas terra do Su.

Quando se fala nas questões agrária e agrícola, remetendo para a atualidade, não se pode esquecer de tecer algumas abordagens sobre os transgênicos. Muito se fala e pouco se sabe, ou pelo menos finge-se que se sabe pouco, acerca dos alimentos geneticamente modificados. Sobre esses alimentos, Porto-Gonçalves (2006) realiza importantes e críticas reflexões de cunho geográfico, isto é, político. De acordo com este pensador, já existe, no momento atual, a subordinação dos grandes latifundiários às grandes empresas responsáveis pela fabricação de sementes geneticamente modificadas e produtos (fertilizantes e adubos) necessários ao seu desenvolvimento. Todas essas empresas são originárias dos grandes países mundiais (Estados Unidos da América, Alemanha, Suíça, Japão, dentre outros).

A subordinação dos latifundiários a essas empresas acontece devido ao que é proporcionado pelos transgênicos. Estes desencadeiam diminuição na necessidade de mão-de-obra, o que 
causa a conseqüente diminuição dos gastos e o aumento dos lucros, pelo menos enquanto as grandes empresas não elevarem exacerbadamente os preços das sementes geneticamente modificadas e dos seus adubos e fertilizantes. Diminuindo a necessidade de mão-de-obra, os transgênicos acabam atendendo as premissas dos grandes latifundiários. Por isso, PortoGonçalves (2006) afirma que a transgenia vem reforçar o modelo de agricultura sem agricultores presente no sistema capitalista atual em âmbito global. Cabe destacar que, no fim das contas, os prejudicados com a expansão dos transgênicos são os trabalhadores e os pequenos produtores rurais, que, cada vez mais, encontram as portas do campo mais fechadas.

É importante salientar que toda essa situação gerada pela modernização conservadora empreendida no campo brasileiro, só é possível por que o Estado a patrocina. Esse patrocínio se dá por meio da liberação de recursos com facilidade para grandes latifundiários adquirirem instrumentos poupadores de mão-de-obra, como máquinas e outros equipamentos. O cerne da questão está no fato de que no Brasil os agentes do estado são os próprios grandes latifundiários, ou quando não, são representantes que atendem prioritariamente aos anseios destes.

Também é mister frisar que neste histórico da questão agrária brasileira, marcada por intensas e comumentes expropriações aos trabalhadores, o aumento do grau de concentração fundiária, na maioria das vezes, esteve ligado a consideração e utilização da terra não como um meio de trabalho para subsistência, mas como uma reserva de valor, um meio para se ter acesso aos créditos rurais e aos incentivos fiscais (SILVA, 1993).

Por fim, diz-se que a agricultura familiar está sendo gradativamente engolida pelo grande capital, resistindo ainda em pequenas áreas interioranas do país (quadro 01). O objetivo dirigente é tornar a agricultura, cada vez mais, um ramo da indústria, excluindo o trabalhador rural do seu meio. Nos dias atuais isso vem intensificando-se, à medida que novas tecnologias do mercado se apossam do meio rural.

Contudo, é válido destacar os pensamentos de Sachs (2002), sobre a agricultura familiar. Este autor frisa que o meio rural brasileiro seria redescoberto e reinventado caso a agricultura familiar fosse considerada e utilizada no desenvolvimento do país. Ele afirma que os pequenos estabelecimentos rurais familiares seriam mais eficientes do que os patronais na geração de renda e empregos, "[...] na medida em que se especializarem em produtos de alta intensidade de mão-de-obra e seu condicionamento e transformação, de maneira a participar mais nas atividades de agregação de valor ao produto primário” (SACHS, 2002, p. 100).

Além disso, aponta que os agricultores familiares contribuem significativamente para a gestão sustentável do espaço rural e dos recursos naturais. Isso ocorre em função de a agricultura camponesa ser multifuncional, produzindo alimentos, outros produtos da terra e da pecuária, bem como atuando como guardiã da paisagem, através da não degradação intensiva dos solos, da vegetação, dos corpos de água etc. As próprias palavras do autor ajudam a compreender as potencialidades que a agricultura familiar possui:

Historicamente, a economia camponesa se perpetuou porque sabia levar em conta o longo prazo, plantando árvores para as gerações futuras e fazendo bom uso da natureza. A racionalidade ecológica moderna nada 
mais é, afinal de contas, que a racionalidade camponesa alçada a outro nível da espiral dos conhecimentos.

Os serviços ambientais prestados pela agricultura familiar respeitosa dos preceitos de manejo ecologicamente sustentável dos solos e das florestas representam fator importante da atratividade turística das regiões rurais, fonte de empregos adicionais para a população local (SACHS, 2002, p. 101).

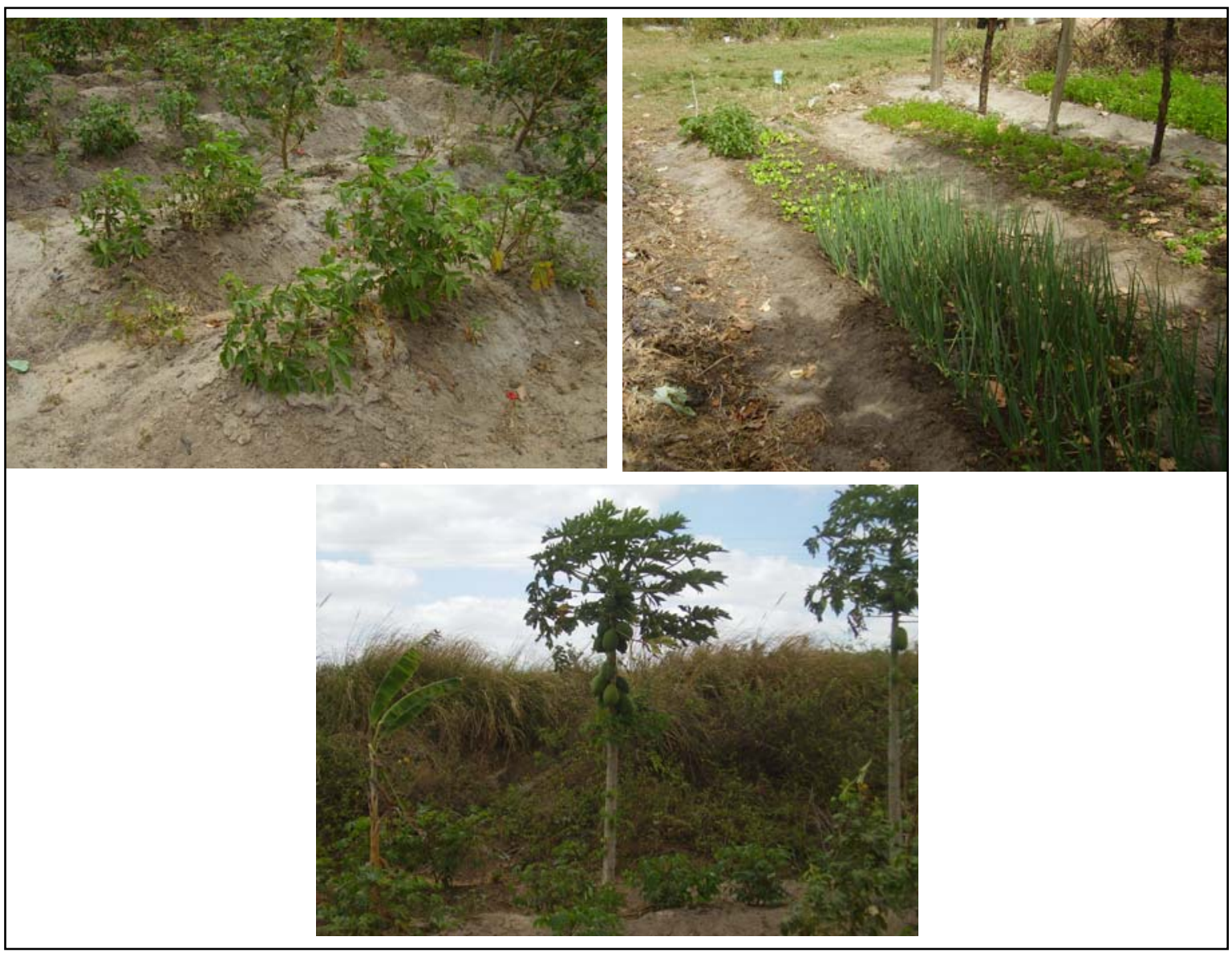

QUADRO 01: ILUSTRAC̣ÕES QUE MOSTRAM CULTIVOS DE SUBSISTÊNCIA NO INTERIOR DO RIO GRANDE DO NORTE. FONTE: PESQUISA DE CAMPO, 2006.

\section{LUTAS AGRÁRIAS: BREVES REFLEXÕES}

"Os inimigos dos camponeses, agora, são os mesmos em todo mundo: as empresas transnacionais e os organismos internacionais que atuam para desenvolver a lógica do capital” (STEDILE, 2007, p. 08).

A partir da década de 1950, a questão agrária no Brasil ganha bastante ênfase. Nos anos que sucedem os acontecimentos que giram em torno dessa questão fazem com que ela ingresse no cenário político para não sair mais. 
É no período que abrange das décadas de 1950 a 1970 que originam-se as Ligas Camponesas e os sindicatos rurais. As Ligas Camponesas surgiram, em meados de 50, em Pernambuco e se expandiram para outros estados da Região Nordeste. Elas foram fundamentais para trazer ao conhecimento nacional os problemas agrários decorrentes da exacerbada concentração fundiária existente na Região Nordeste e em todo o Brasil.

As Ligas Camponesas defendiam a organização política dos camponeses, para que estes lutassem pela reforma agrária. De acordo com as concepções das ligas, todos os males existentes em âmbito nacional seriam decorrentes do grande monopólio sobre a terra e, por isso, se fazia urgente uma revisão da estrutura agrária brasileira.

Data do início dos anos de 1960, o aparecimento no cenário brasileiro dos sindicatos rurais. Estes eram fortemente influenciados pela Igreja, e lutavam por melhores condições de vida e de trabalho para os assalariados do campo.

Com o golpe militar de 1964, implantou-se no Brasil um regime governamental ditatorial, que procurou de imediato silenciar e/ou amortecer as discussões sobre a questão agrária nacional. Com isso, as Ligas Camponesas foram suprimidas e os sindicatos rurais distorcidos, passando a comungar dos ideais governamentais.

Todavia, estas medidas não conseguiram abafar significativamente os problemas agrários brasileiros. Sendo assim, o governo ditatorial resolveu tratar a questão agrária de maneira institucional, promulgando, em 1964, o Estatuto da Terra. Esse estatuto representava a proposta governamental de resolução para os problemas agrários do país. O Estatuto da Terra nada mais fez do que explicitar que os objetivos do governo militar eram obscurecer a proposta de uma reforma agrária ampla, isto é, em âmbito nacional, e colocar em tela iniciativas insuficientes e pontuais de colonização de algumas famílias.

Em fins da década de 1970, começam a ocorrer no Brasil sinais de uma tímida abertura política. Dessa forma, no início da década de 1980, os sindicatos firmam-se como mediadores dos conflitos existentes entre proprietários latifundiários e trabalhadores rurais. Nesse contexto, segundo Andrade (1997), os sindicatos conquistam expressivas vitórias, como o estabelecimento de um piso salarial diferenciado para os canavieiros, a realização de uma campanha salarial unificada na Região Nordeste, a exigência de pagamento de horas extras aos trabalhadores, a manutenção de uma tabela de tarefas pré-definidas e a extensão da Previdência Social ao trabalhador do campo.

Contudo, no final dos anos 80, a ação sindical entrou em crise, em função dos problemas enfrentados por vários setores econômicos no Brasil, inclusive o agrícola, e da aceleração das transformações capitalistas nas relações de trabalho e de produção. Essas transformações geraram altos índices de desemprego e a intensificação da expulsão dos trabalhadores rurais para as periferias urbanas. Além disso, nesse momento, entrou em moda a prática de contratação temporária para a realização dos trabalhos do campo, o que prejudicou mais ainda a organização e a vida dos trabalhadores rurais.

A evidência de que as condições de vida e de trabalho do homem rural no Brasil continuavam se deteriorando, fez intensificar-se, na década de 80 , a luta pela reforma agrária. Nessa luta, ganha destaque, a partir de 1989, o Movimento dos Sem-Terra (MST). 
O MST passou a atuar com manifestações de protesto e ocupações de grandes latifúndios improdutivos existentes no território nacional. Em detrimento disso, ocorreram, durante a década de 1990, inúmeros conflitos entre os trabalhadores do movimento e grandes proprietários rurais. Nesses conflitos, os grandes proprietários utilizavam-se de jagunços armados, o que ocasionou a morte de muitos trabalhadores.

$\mathrm{Na}$ atualidade, o MST continua a sua peregrinação em busca de terras para os trabalhadores produzirem. Setores da sociedade, apoiados pela mídia, ridicularizam esse movimento, o estereotipando como sendo um grupo composto por desocupados e oportunistas que querem tomar as terras dos homens de bem do país (ilustração 01).

Mas a verdade é que o MST representa os esquecidos pelo grande capital, homens, mulheres e crianças que não têm acesso a quase nada: trabalho, educação e saúde de boa qualidade, direito a lazer etc. São pessoas que vivem a mercê dos setores dirigentes da sociedade, que ficam localizados em margens de estradas arriscando suas vidas em busca de dias melhores (quadro 02). Ao perguntar a um trabalhador sem-terra que vive atualmente na margem direita da BR 304 (sentido Natal-RN - Mossoró-RN), à espera de um "pedaço de chão" para produzir, quais são as suas expectativas na vida, ele respondeu: "a expectativa é viver até quando Deus quiser. Depois, alguém leva para o cemitério e enterra”.

Todas as lutas dos trabalhadores rurais têm apenas um fim pretendido: a conquista pelo direito a terra para conseguir a subsistência e a possibilidade de viver dignamente. Se esse fim fosse considerado e atendido pelos homens do poder no Brasil, vários conflitos e sofrimentos teriam sido e seriam evitados. A reforma agrária representa esse fim pacífico, dando o direito ao trabalhador de produzir na terra que encontra-se improdutiva.

O grande percalço é que no sistema capitalista "[...] pouco importa que um pedaço de chão produza soja, cana-de-açúcar ou feijão. O que interessa é que produza lucros” (SILVA, 1993, p. 104). E esses lucros devem sempre estar nas mãos dos grandes latifundiários.

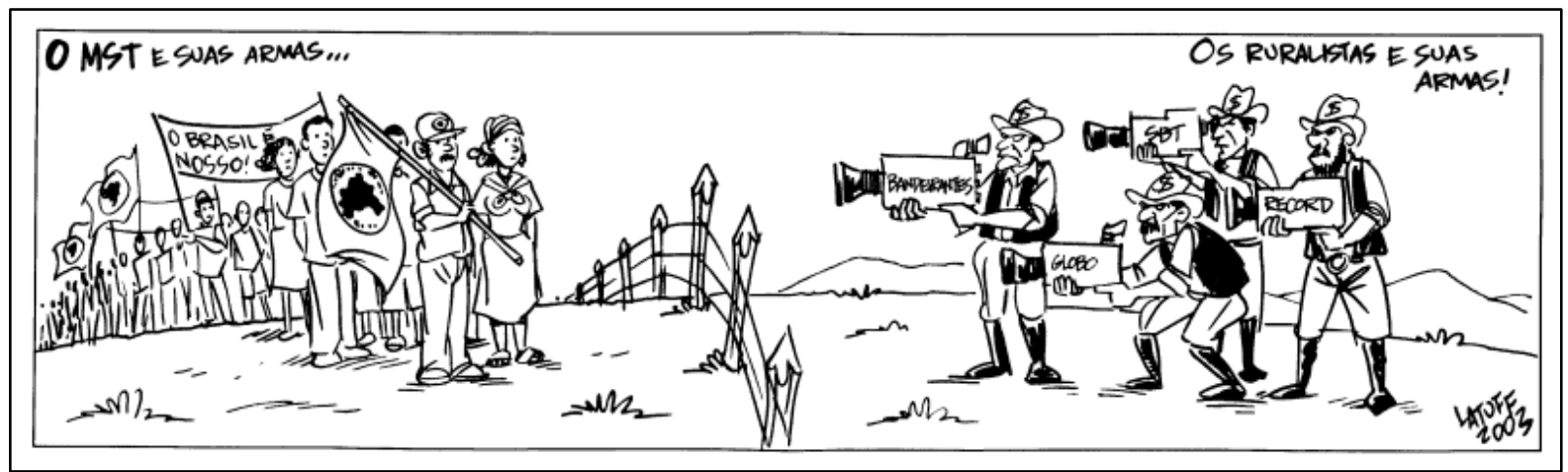

ILUSTRAC̣̃̃O 01: CHARGE MOSTRANDO AS ARMAS UTILIZADAS, NA LUTA AGRÁRIA BRASILEIRA, PELO MST E PELOS GRANDES LATIFUNDIÁRIOS

FONTE: 〈http://www.midiaindependente.org/pt/blue/2003/07/259755.shtml >. Acesso em 04 jan. 2007. 


\section{PALAVRAS FINAIS: A GRANDE ESPERANÇA - REFORMA AGRÁRIA}

"[...] a reforma agrária é hoje - mais do que nunca - uma questão eminentemente política. [...] não é mais o direito de cada um à sua propriedade, mas o direito dos trabalhadores ao resultado da sua produção" (SILVA, 1993, p. 106).

A reforma agrária é o grande anseio dos trabalhadores e dos pequenos produtores rurais. Mas o que seria essa reforma tão pretendida por aqueles que são desfavorecidos no sistema dominante?

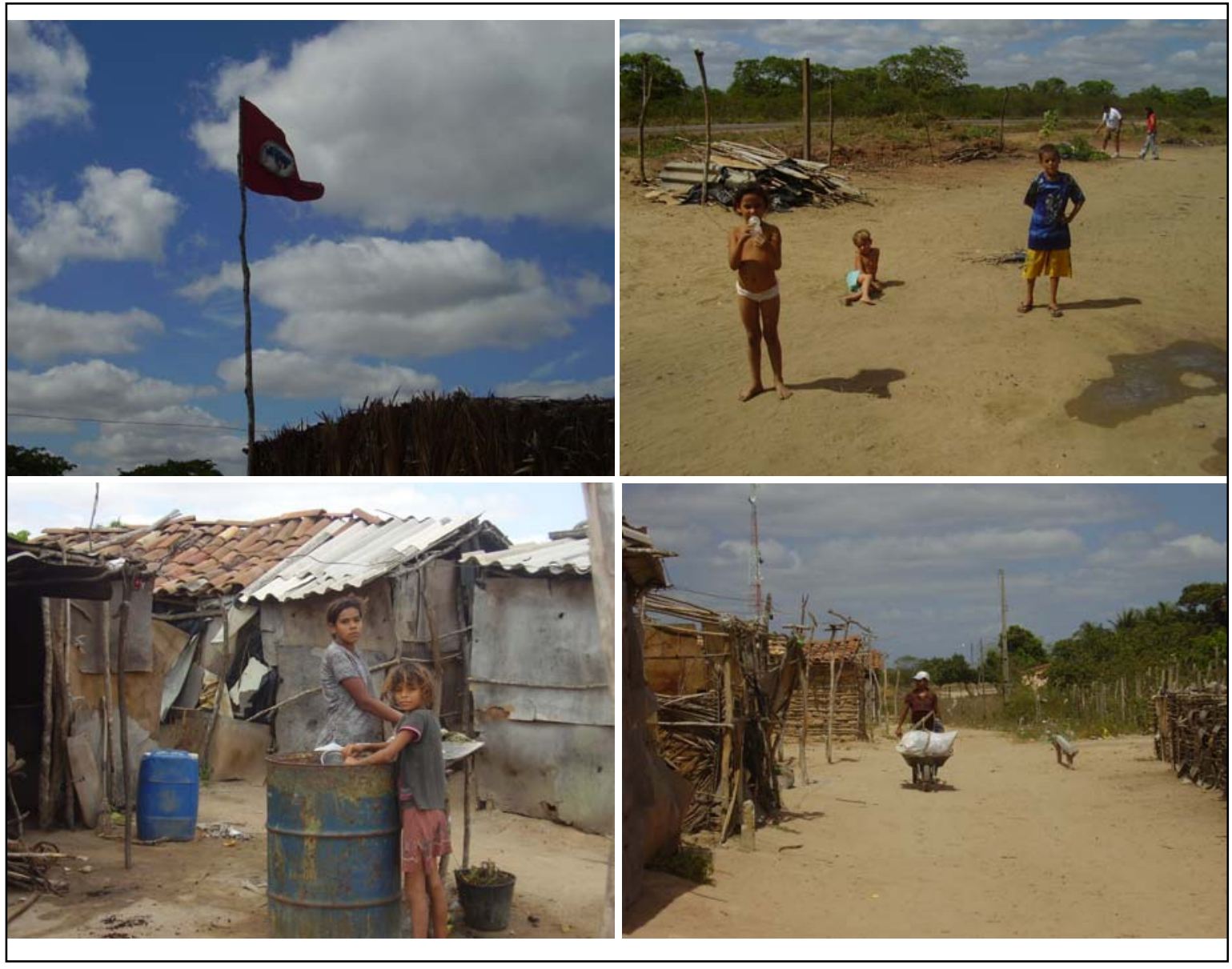

\footnotetext{
QUADRO 02: ILUSTRAC̣ÕES MOSTRANDO A SITUACุÃO PRECÁRIA EM QUE VIVEM OS TRABALHADORES SEM-TERRA NAS MARGENS DAS ESTRADAS NO RN FONTE: PESQUISA DE CAMPO, 2006.
}

Para os trabalhadores e pequenos produtores rurais, a reforma agrária não é, ao contrário do que muitos propagam ser, a pulverização econômica da terra, pelo contrário, é a transformação desta em instrumento produtivo favorável a todo o meio social. É acabar com a improdutividade fundiária, é redistribuir renda, poder e direitos, como também gerar empregos. 
Mas como poderia ocorrer essa reforma? A reforma agrária nada mais é do que uma estratégia dos trabalhadores rurais para acabar com o grande monopólio sobre a terra, bem como com a improdutividade que reina em grandes latifúndios (ilustração 02). É também uma maneira de fazer com que os trabalhadores possam colher os frutos do seu próprio trabalho, deixando de ser expropriados.

Para que essa reforma aconteça é necessário que o grande latifúndio, sobretudo o improdutivo, deixe de existir, transformando-se em pequenas propriedades produtivas pertencentes aos verdadeiros trabalhadores do campo. Esse pensamento coaduna com as palavras de Silva (1993, p. 95):

[...] é necessário eliminar o latifúndio e incidir sobre a dominação parasitária da terra, desde o caso daqueles que deixam a terra inculta à espera de valorização imobiliária, até os que a utilizam para repassar recursos financeiros aos pequenos produtores rurais.

Há um certo tempo que a reforma agrária vem sendo discutida no Brasil, sob diferentes enfoques. Nos anos de 1950, as discussões sobre essa reforma giravam em torno da industrialização brasileira. Temia-se que a agricultura gerasse empecilhos para a industrialização do país, em função do setor agrícola, segundo as autoridades da época, ser incapaz de aumentar a sua produtividade. Com isso, esse setor não atenderia às necessidades de produção de alimentos e matérias-primas, que eram crescentes.

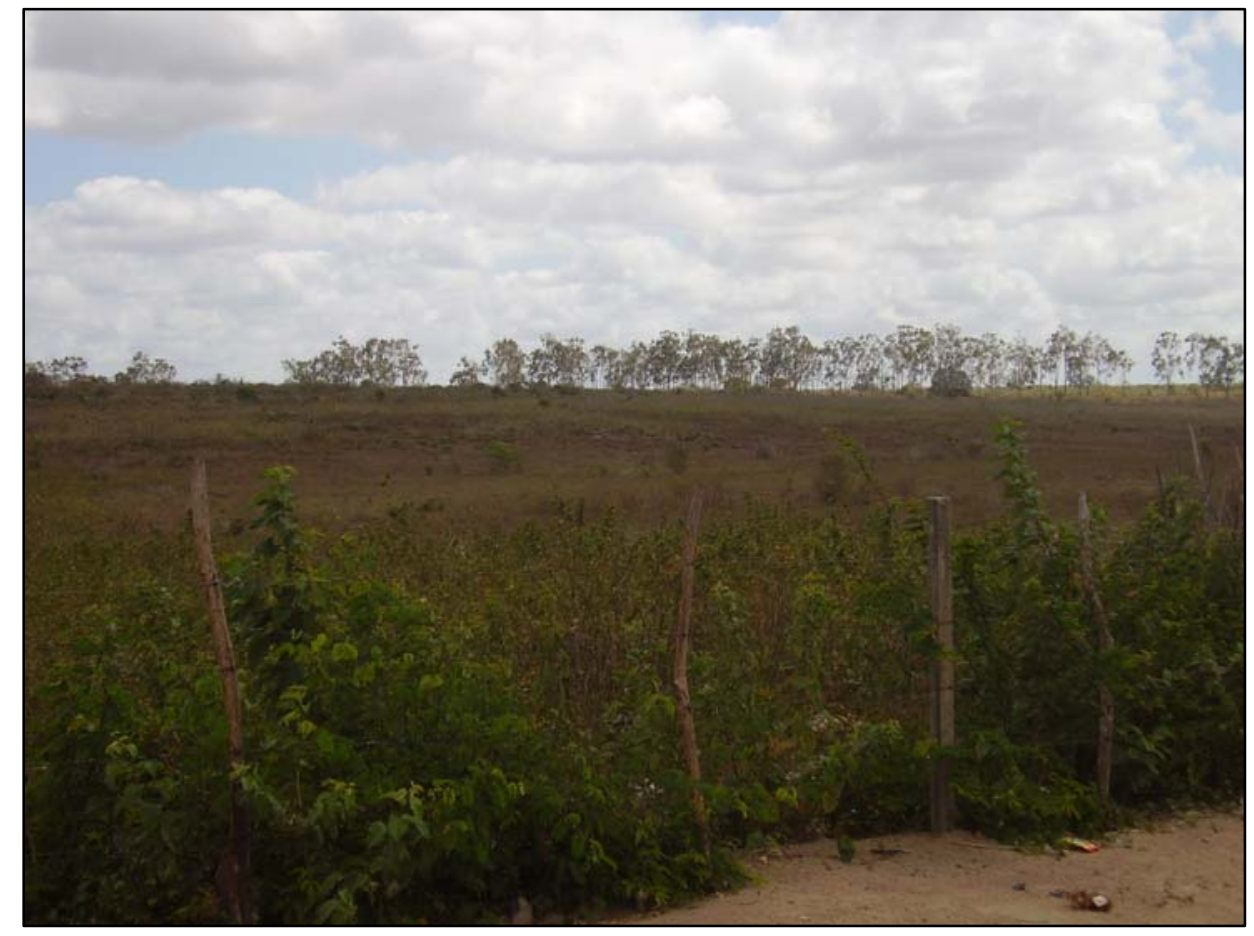

ILUSTRAÇÃO 02: GRANDE LATIFÚNDIO IMPRODUTIVO

NO RIO GRANDE DO NORTE

FONTE: PESQUISA DE CAMPO, 2006. 
Dessa forma, no fim dos anos 50, a burguesia via na reforma agrária um meio de se obter o aumento da produção. Todavia, o que aconteceu, com o nome de reforma, foi a intensificação da concentração fundiária no país. Sendo assim, pode-se dizer que a medida discutida e realizada nos anos 50, não era agrária, mas sim agrícola, porque tinha um único objetivo: aumentar a produtividade agrícola para elevar os lucros da burguesia.

$\mathrm{Na}$ atualidade, a reforma esperada, por parte dos trabalhadores rurais, é a agrária. A burguesia é e sempre foi totalmente contrária a essa reforma. A reforma agrária dos dias de hoje não é mais uma simples reivindicação por terra, mas também por direitos, por dignidade, por qualidade de vida. Diante disso, pode-se denominá-la também de "revolução agrária”, pois, para que esta aconteça é necessário que haja mudanças na lógica que perpassa atualmente o campo brasileiro, como, por exemplo, a lógica da grande propriedade fundiária improdutiva.

A reforma agrária é nos dias em que se vive uma questão política. É inconcebível que um país que pretende sair da posição de emergente para a de desenvolvido prossiga com políticas públicas imediatistas e insuficientes, e com uma estrutura agrária desigual, excludente e ridícula. É inaceitável que a única preocupação de um Estado seja a econômica. O Estado tem que ser social e democrático, o que é um direito de todos.

Assim como declara Silva (1993), defende-se que a questão agrária brasileira depende do traçado democrático adotado no país. Quem escolhe esse traçado são todos os indivíduos da população, inclusive os trabalhadores rurais. É preciso ter esperanças, é preciso lutar, é urgente exigir mudanças. Senão, tudo estará perdido nas mãos de uma burguesia capitalista, faminta por lucros e desinteressada com o bem-estar social coletivo.

\section{REFERÊNCIAS}

1. ANDRADE, M. C. de. A terra e o homem no Nordeste. São Paulo: Cortez, 2005.

2. ANDRADE, S. M. C. de. A questão agrária no Nordeste. São Paulo em Perspectiva, v. 11, n. 2, 1997.

3. ARAÚJO, T. B. de. Nordeste, Nordestes: que Nordeste? Disponível em: <http://www.fundaj.gov.br/observanordeste/obte013.html>. Acesso em 02 jan. 2007.

4. ASSARÉ, P. do. Cante lá que eu canto cá: filosofia de um trovador nordestino. Petrópolis: Vozes, 1986.

5. BAUER, G. G. T. Sobre as origens da questão agrária brasileira. Revista de História Regional, Ponta Grossa, v. 3, n. 1, verão de 1998.

6. MARTINS, J. de S. O poder do atraso. Ensaios de Sociologia da História lenta. São Paulo: Hucitec, 1994.

7. ______. Os camponeses e a política no Brasil: as lutas sociais no campo e seu lugar no processo político. Petrópolis: Vozes, 1984.

8. OliVEIRA, A. U. de. A geografia das lutas no campo. São Paulo: Contexto, 2001.

9. PORTO-GONÇALVES, C. W. A globalização da natureza e a natureza da globalização. Rio de Janeiro: Civilização Brasileira, 2006.

10. SACHS, I. Desenvolvimento humano, trabalho decente e o futuro dos empreendedores de pequeno porte no Brasil. Brasília: Edição Sebrae, 2002.

11. SANTOS, M. Por uma outra globalização: do pensamento único à consciência universal. Rio de Janeiro: Record, 2003. 
12. SILVA, J. G. da. O novo rural brasileiro. Campinas: UNICAMP, 1999.

13. . O que é questão agrária. São Paulo: Brasiliense, 1993.

14. STEDILE, J. P. A conjuntura internacional da agricultura e suas conseqüências para o mundo camponês. Disponível em: <http://www.fsmm2006.org/PDF/37\% 20Sem\%20A\%20conjuntura\%20internacional\%20da\%20\%20agricultura\%20Stedile.pd f>. Acesso em: 04 jan. 2007.

15. ______ A origem do latifúndio no Brasil. Disponível em: <http://www.midiaindependente.org/pt/blue/2003/07/259755.shtml>. Acesso em: 04 jan. 2007. 